\title{
Alteridade, Pesquisa na Educação em Ciências e a Perspectiva Freireana
}

\author{
Alterity, Research in Science Education and the Freirean Perspective
}

Demétrio Delizoicov, Antonio Fernando Gouvêa da Silva

Palavras-chave Resumo A pluralidade de iniciativas que consideram conhecimentos

Educação em prévios de estudantes é sinteticamente caracterizada neste artigo ciências; através de uma revisão de literatura. Tais iniciativas têm como Alteridade; fundamentação distintos pressupostos educacionais, epistemológicos,

Dussel; psicológicos e axiológicos que direcionam tanto opções didáticas Paulo Freire; para a abordagem dos conteúdos científicos como a própria seleção Currículo dos conteúdos que compõem os programas de ensino. Através ético-crítico. de uma revisão de literatura o artigo aborda as especificidades da contextualização da concepção de educação de Paulo Freire, bem como a contribuição de Enrique Dussel para a dimensão axiológica do currículo, considerando o âmbito da educação escolar. Busca-se resposta para a seguinte questão: qual a perspectiva axiológica que fundamenta a alteridade na implementação da concepção freireana na educação escolar? São analisadas as relações estabelecidas com princípios curriculares construídos por várias redes públicas de ensino fundamental tendo como fundamentos as concepções desse educador sobre aspectos ontológicos, gnosiológicos e axiológicos que sustentam a sua concepção de alteridade na relação essencial com processos educacionais. São relacionadas as suas concepções com as que o filósofo Enrique Dussel aponta para uma educação ética-crítica de modo a estabelecer uma organização de prática pedagógica para a Educação em Ciências que tenha na alteridade seu compromisso ético-crítico. 
Keywords Abstract This paper presents a systematic literature review on Science education; the several initiatives that consider prior knowledge of students. alterity; These initiatives are based on distinct educational, epistemological, Dussel; psychological and axiological presumptions that steer both didactic Paulo Freire; options for approaching scientific concepts and the selection of Ethical-critical concepts to compose educational programs. Our objective is to curriculum. address specificities in Paulo Freire's concept of education, as well as contributions by philosopher Enrique Dussel to the axiological dimension of curriculum, considering the realm of school education - in an effort to answer the following question: what is the axiological perspective that supports alterity in the implementation of Freirean concepts in school education? We analyze the principles of educational programs from several public-school networks, based on Freire's concepts related to ontological, gnoseological and axiological aspects that support his concept of alterity in the essential relation with educational processes. His concepts are then compared with Dussel's suggestions for an ethical-critical education, so that we organize an ethical-critical pedagogical practice for science education that is committed to alterity.

\section{Introdução}

Por força de uma institucionalidade legal, advinda de novas constituições e emendas constitucionais, a educação escolar no Brasil enfrenta o desafio de promover a inclusão de amplas camadas sociais que, historicamente, foram alijadas do seu direito à educação. Assim é que, após cerca de um século e meio da independência e quase 80 anos após a Proclamação da República, o ensino fundamental obrigatório passou de quatro para oito anos, a partir de 1969. Foi preciso a virada do milênio para que, apenas quase ao final da primeira década do século XXI, uma educação básica com 12 anos se tornasse obrigatória. Por sua vez, em 2012, devido à Lei de Cotas, ampliou-se significativamente a presença no ensino universitário da população afrodescendente, como também passaram a frequentar a universidade estudantes de várias etnias indígenas.

Envolvida nesse desafio inclusivo, a comunidade de pesquisadores em Educação em Ciências (EC) tem se dedicado, de modo mais intenso e frequente, aos problemas de investigação implicados na inclusão escolar originada da diversidade e pluralidade sociocultural de estudantes que, anteriormente a essas legislações, não eram significativamente presentes no espaço escolar. Um levantamento sistemático de publicações em congressos e revistas da área de EC sobre o tema dessa diversidade, presente nos vários níveis de ensino, ainda está por ser realizado. Contudo, pode-se notar relativo aumento de publicações, no Brasil, com esse foco, a partir do final da primeira década de 2000, tais como Candau (2008), Oliveira e Candau (2010) que 
abordam o tema da interculturalidade e de Santos e Menezes (2010) que se ocupam do tema do conhecimento em países colonizados por europeus. Dentre outros, esses autores encontram-se citados em pesquisas da EC a respeito da necessária alteridade a ser aprofundada e implementada, considerando a diversidade e pluralidade sociocultural presente contemporaneamente na educação escolar brasileira. São exemplos de pesquisas em EC que se ocupam com a perspectiva da alteridade imposta por essa situação: Oliveira et al. (2019) que têm como foco um ensino de física cujo compromisso é com relações sociais éticas; Pinheiro (2019), ao tecer considerações sobre EC e relações étnico-raciais; e, semelhante ao anterior, o trabalho de Alves-Brito e Massoni (2018); ainda, Oliveira e Queiroz $(2017,2015,2013)$, cujos livros se debruçam sobre distintos aspectos que compõem a EC na perspectiva dos Direitos Humanos.

Não obstante esse tratamento contemporâneo, a alteridade, enquanto objeto de pesquisa na EC, têm presença inicial desde finais da década de 1970. É certo, com outras perspectivas educacionais, psicológicas e epistemológicas, tendo em vista que, hegemonicamente, as pesquisas desse período tinham como foco problemas de ensino e aprendizagem de alunos com perfis distintos dos atuais. No entanto, o cenário que caracterizou o início das pesquisas sobre alteridade em EC foi se modificando ao longo das duas décadas finais do século XX.

Uma síntese das pesquisas permeadas pela perspectiva da alteridade na Educação em Ciências (EC) dominantes naquelas duas décadas é fornecida em conhecido trabalho (Pfund \& Duit, 1994) no qual se apresenta um amplo e significativo levantamento das publicações em EC que se relacionam com alteridade. Distintas designações foram utilizadas para contemplar focos de pesquisa cuja preocupação era com o conhecimento que o aluno já possuía antes do ensino de determinados conceitos científicos a serem abordados em atividades educativas: concepções espontâneas, concepções prévias, concepções alternativas, mudança conceitual, dentre outras (Lemgruber, 2000).

Com essas designações se originaram pesquisas até o final dos anos 1990 e início do século XXI, quando, então, o papel da alteridade na EC passou a contemplar, de modo mais frequente, outros aspectos ainda não considerados significativamente, embora já presentes, em algumas publicações do período anterior. Em particular, destacam-se as publicações em EC que fundamentam perspectivas sobre a alteridade a partir da Filosofia da Linguagem e da Análise do Discurso (Almeida et al., 2008), dos Estudos Culturais (Wortmann \& Veiga-Neto, 2001) e a da educação dialógica freireana (Delizoicov, 2008; Silva, 2004; Delizoicov, 1983). Por sua vez, são cada vez mais presentes os trabalhos sobre alteridade publicados nas atas dos últimos ENPECs, em suas várias formulações teóricas. É de se destacar um relativo deslocamento teórico e de concepções no enfoque da alteridade, quando comparado com o tratamento anterior (Pfund \& Duit, 1994; Lemgruber, 2000). De fato, parecem emergir compreensões, sobretudo ontológica de ser humano, distintas das que eram presumidas nas pesquisas sobre concepções alternativas e mudança conceitual. Os impactos dessa emergência incidem diretamente nas reflexões gnosiológicas e educacionais que passam a incorporar pressupostos das pesquisas em 
EC direcionadas à alteridade e seu tratamento didático-pedagógico, tanto na educação escolar como na não escolar.

Por sua vez, considerações de caráter axiológico também precisam de explicitação, de modo que contribuam para o aprofundamento do papel da alteridade. Ainda que em Freire sejam estabelecidas relações entre valores e alteridade, como se anuncia, por exemplo, no título de três de seus livros: Educação como prática de liberdade, Pedagogia do Oprimido e Ação Cultural para a Liberdade, é fundamental aprofundar as relações quando o desafio é a contextualização das concepções filosófico-educacionais desse autor no âmbito da educação escolar. Assim: qual a perspectiva axiológica que fundamenta a alteridade na implementação da concepção freirena na educação escolar? Neste sentido, o objetivo deste artigo consiste em tornar explicitas as relações implicadas entre valores e alteridade em Freire.

\section{Alteridade na concepção de Freire}

A dimensão axiológica, tanto no que se refere às concepções de alteridade, como também em premissas que sustentam concepções educacionais e gnosiológicas que fundamentam proposições curriculares e didáticas, desde as de Comenius até as contemporâneas, nem sempre é total ou convenientemente explicitada. Contudo, distintos valores têm originado distintas e conflitantes implementações de práxis curriculares, inclusive as que explicitamente defendem a necessidade segundo a qual o conhecimento de estudantes precisa estar nelas contemplado, ou seja, atribuem algum papel à alteridade, tanto nas análises teóricas como em práticas de ensino por elas fundamentadas, nas correspondentes implementações curriculares.

Assim, neste artigo ao se aprofundar as relações entre valores e alteridade em Freire, são abordados aspectos de práxis curriculares que são fundamentadas na sua concepção de educação e que subsidiaram processos de construção curricular em escolas de redes públicas de ensino no Brasil. A implementação pioneira (Delizoicov, 2008; Torres et al., 2002; Sampaio, 1994; Pontuschka, 1993) dessa construção, que tem sido denominada de Movimento de Reorientação Curricular (MRC), ocorreu durante a gestão de Freire (1995) como secretário da educação do município de São Paulo. Os desdobramentos (Saul, 2016, 2012) dessa iniciativa ocorreram em proposições e construções curriculares de escolas de redes públicas de ensino (Silva, 2004).

Vários estudos têm tido como foco essas construções curriculares, abordando suas distintas dimensões, a exemplo de Delizoicov et al. (2013), que se ocupam do processo de reorientação curricular na concepção freireana de educação, ao examinar dissertações que se dedicaram à análise desse processo; de Delizoicov et al. (2018), no qual são apresentadas especificidades relativas à reorientação curricular freireana implementada pela secretaria municipal de educação de Chapecó em sua rede de ensino; de Saul e Silva (2009), que examinam o legado de Freire para as políticas públicas de currículo e para a formação de educadores; e de Silva (2004) que, ao se dedicar à análise de Movimentos de Reorientação Curricular efetivados por cerca de uma dezena de secretarias de educação 
e implementadas em suas respectivas redes de ensino, aprofunda aspectos filosóficos, gnosiológicos e axiológicos envolvidos na práxis originada nesses processos, bem como relata e analisa como eles foram implementados.

Ademais, Delizoicov et al., subsidiados por um exame da literatura a respeito dos MRC freireanos, estabelecem:

[...] aspectos da ontologia e da gnosiologia que fundamentam a concepção de formação permanente em Paulo Freire. Por meio do resgate de publicações, foca-se a ocorrência de ações formativas embasadas nessa perspectiva conceitual implementadas em redes públicas de ensino que adotaram premissas freireanas para a construção de currículos escolares. (Delizoicov, 2020, p. 353)

Especialmente em Extensão ou Comunicação? (Freire, 1977) e Pedagogia do Oprimido (Freire, 1988), o educador apresenta e aprofunda suas concepções ontológica e gnosiológica com as quais fundamenta uma práxis educativa relativa a três categorias que têm sido basilares na estruturação dos processos de reorientação curricular, quais sejam: dialogicidade, problematização e interdisciplinaridade. Destaca-se que essas três categorias constituem uma trindade cuja característica é sua indissociabilidade, sem a qual a construção histórica de uma reorientação curricular freireana não seria possível. Delizoicov (2020, p. 7), em depoimento, informa:

[...] [nas] análises realizadas com aporte nas obras de Freire ... o maior impacto foi a respeito do conceito de interdisciplinaridade. De fato, os vários significados desse termo, ... nem sempre contemplam o saber do educando e do agrupamento do qual faz parte! A emergência dessa compreensão representou um salto nas nossas práxis. Marta Pernambuco, professora da UFRN ... já havia destacado esse aspecto, fruto tanto do aprofundamento nas leituras que fazíamos de Freire como da reflexão propiciada pelo desenvolvimento do projeto Ensino de ciências a partir de problemas da comunidade, por ela coordenado na região nordeste do Brasil. Marta já chamava a atenção para o fato de que a dimensão dialógica da concepção freireana deveria ser implementada não apenas no diálogo com os educandos na situação da sala de aula, mas antes mesmo de ocorrerem. Em outros termos, quando há o desafio de construir um currículo ... interdisciplinar, não seriam apenas ... os conceitos pertencentes às várias disciplinas que historicamente vêm constando como componentes de currículos. ... Fundamental, na perspectiva freireana, é a inserção de conhecimentos e de práticas originários da produção cultural dos agrupamentos humanos com os quais se estabelecem ações educativas dialógicas. (grifo nosso)

A indissociabilidade entre dialogicidade, problemas e interdisciplinaridade é decorrência de pressupostos ontológicos de Freire sobre o sujeito do conhecimento e do próprio conhecimento. O núcleo central que fundamenta a perspectiva da alteridade em Freire reside tanto na indissociabilidade dessas três categorias como nos pressupostos ontológicos dele que, de fato, articulam-se com a sua axiologia, conforme se pretende 
explicitar ao longo deste artigo.

Para Freire, o sujeito do conhecimento é um ser humano inconcluso (Freire, 1988 ; 1977) que se constitui na sua relação com outros seres humanos, bem como com o mundo, quer o natural quer o transformado pelos seres humanos. Na sua concepção, processos educativos devem contribuir para a humanização (Severino, 2006) do ser humano, uma vez que a humanização é um processo histórico e permanente. Freire caracteriza, assim, uma constituição do ser humano que é um devir, mas não qualquer devir! Para ele, é um devir cujo sentido é o de um ser mais ... humano (Freire, 2010).

Por sua vez, Freire $(1977,1988)$ concebe o conhecimento como incompleto. É porvir! Essa característica da incompletude do conhecimento tem um papel fundamental na concepção de educação de Freire. Docentes das ciências da natureza, além de pesquisadores dos fenômenos naturais, convivem com essa incompletude do conhecimento produzido pelas Ciências Natureza. São exemplares dela:

1) as teorias científicas originadas dos distintos modelos para o universo: desde a concepção de uma Terra plana, passando pelos modelos geocêntrico, heliocêntrico, galactocêntrico, Big Bang, Big Bang inflacionário (Steiner, 2006). A respeito desses modelos, esse autor argumenta: "Cada modelo explica o que era conhecido na época e o que as medidas de então podiam confirmar. Não se pode dizer que essas teorias estavam erradas. Seria melhor afirmar que eram incompletas" (Steiner, 2006, p. 6, grifo nosso);

2) as teorias científicas sobre a vida e a sua reprodução, que de modo semelhante ao que argumenta Steiner (2006) podem ser consideradas incompletas se tivermos como referência as explicações de Darwin para a origem das espécies, as leis da hereditariedade de Mendel, a teoria sintética e o modelo do DNA;

3) de modo análogo, os modelos científicos para a constituição microscópica da matéria.

Assim concebidos, o sujeito do conhecimento e o conhecimento por ele produzido, Freire $(1977,1988)$ constrói uma gnosiologia, em consonância com essas ontologias, com a qual fundamenta sua concepção de educação. Freire dedica espaço privilegiado na sua obra aos problemas, por ser no enfrentamento deles que, em sua trajetória, o Homo sapiens constrói o seu processo de humanização no qual conhece e transforma a natureza. Isso se dá, em princípio, para sobreviver, e com isso o ser humano constrói relações humanas e sociais capazes de ir compartilhando os conhecimentos em construção, o que o caracteriza como um ser produtor de cultura que tem uma história, ou seja, uma temporalidade que ocorre em determinado espaço e, portanto, uma produção cultural espaço-temporalmente contextualizada. É essa produção cultural que tem a propriedade, segundo Freire, de direcionar ações humanas no enfrentamento de problemas, enfrentamento que ocasiona um porvir criativo, na medida em que também alavanca a emergência de conhecimentos inéditos.

Em Pedagogia do Oprimido, Freire (1988) aprofunda essa compreensão, fundamentando-se em duas categorias usadas por Goldmann (1980), denominadas consciência real efetiva e consciência máxima possível, ambas históricas. Elas se 
constituem como porvir. A relevância desses dois tipos de consciência para análises histórico-gnsiológicas é que em determinadas situações espaço-temporais convivem, simultaneamente, a presença de compreensões que poderiam ser relacionadas a essas duas categorias, como é o caso típico da educação escolar. Isso se dá quando conhecimentos históricos já produzidos a partir de problemas formulados e enfrentados, o que representa, num determinado momento a consciência máxima possível, podem ainda não estar sendo compartilhados por estudantes, não obstante já existam e estejam disponibilizados. São, portanto, conhecimentos que, inéditos para eles, precisam ser adequadamente abordados pela educação escolar.

Relativamente às ciências da natureza e ao seu ensino, os exemplares mencionados anteriormente quanto à incompletude dos conhecimentos a respeito do universo, da vida e do átomo podem ser entendidos com as perspectivas da consciência real efetiva e da consciência máxima possível. Seriam, então, associados à consciência máxima possível as explicações contemporâneas contidas no modelo do DNA, do Big Bang inflacionário e o da Mecânica Quântica, respectivamente, para a vida e sua reprodução, para o universo e para o átomo. As demais explicações mencionadas são associadas à consciência real efetiva, numa interpretação que está em acordo com as considerações gnosiológicas de Freire. Contudo, também é necessário que se conheça o nível de consciência real efetiva de aprendizes, caso haja, sobre o problema que foi resolvido e cujo conhecimento que se originou venha a ser parte dos currículos escolares. Destaca-se, pois, uma das características da alteridade contempladas pelas análises gnosiológicas de Freire e que têm seus desdobramentos nas suas proposições educacionais. Particularmente, a contribuição que conhecimentos oriundos das ciências da natureza podem dar para a constituição do ser mais, na perspectiva da alteridade freireana, implica que educadores estabeleçam práticas educativas que oportunizem a emergência da consciência real efetiva, compartilhada por aprendizes a respeito de situações vividas que estão inviabilizando o seu ser mais.

Há, portanto, outra dimensão da alteridade na concepção de educação de Freire. Trata-se de identificar as situações nas quais vivem aprendizes, seus familiares e grupo social com o qual convivem cotidianamente e que, de algum modo, estariam impedindo o desiderato de um ser mais. Quais seriam essas situações? Freire, então, aponta a busca e o entendimento dessas situações como sendo um problema a ser enfrentado por docentes. Quais seriam as compreensões e explicações de estudantes e seu grupamento social sobre elas? Elas constituem a dimensão mais relevante da alteridade na proposta freireana! Ao se relacionar as compreensões e as explicações obtidas com o nível de consciência sobre elas, docentes de determinada escola, em equipe, têm condições de planejar as ações educativas tendo como referência a consciência máxima possível a ser alcançada por aprendizes ao problematizar, numa perspectiva da dialogicidade, o nível de consciência real efetiva que está sendo explicitado.

Compartilhando a afirmação de Bachelard (1977, p. 148), segundo a qual "é preciso saber formular problemas. ... todo conhecimento é uma resposta a uma 
pergunta”, Freire, na relação que estabelece entre a sua perspectiva educativa e as análises gnosiológicas que apresenta, argumenta que é a qualidade dos problemas propostos que direciona um processo educativo que persegue o desiderato do ser mais. Freire, então, argumenta e propõe uma educação como situação gnosiológica, caracterizada em um dos itens, com esse mesmo título, no livro Extensão ou Comunicação? (Freire, 1977). Os problemas que Freire atribui qualidade de terem potencial de contribuir para a humanização existem em sua materialidade e se referem às contradições que os seres humanos precisam superar para que se humanizem, no sentido de ser mais.

Assim fundamentada a sua perspectiva gnosiológica, Freire propõe procedimentos que viabilizem uma práxis educativa direcionada à busca, por equipes de docentes, das manifestações, materialmente detectadas nos locais onde atuam, de contradições globais que limitam a emergência do ser mais. Dentre outras dessas contradições globais, exemplificam-se: (1) a fome, conforme recentes e seguidos relatórios sobre o "Estado da segurança alimentar e nutrição no mundo", emitidos pela FAO (Organização das Nações Unidas para a Alimentação e a Agricultura);(2) o desemprego, segundo a OIT(Organização Internacional do Trabalho/ONU) e (3) a mudança climática que cada vez mais é pauta de discussão em vários organismos internacionais. Freire aprofunda os procedimentos propostos para a busca desse tipo de manifestação envolvendo contradições no livro Pedagogia do Oprimido (Freire, 1988), ao apresentar o que denominou de investigação temática. A adoção criativa desses procedimentos em movimentos de reorientação curricular é amplamente relatada e analisada pela literatura, a exemplo das publicações já referidas anteriormente sobre esses movimentos.

Sinteticamente, neles são desenvolvidas as etapas com as quais as equipes docentes podem promover uma educação como situação gnosiológica, ao articular: (1) a busca das manifestações locais de contradições globais: os problemas a serem enfrentados com a contribuição de processos educativos; (2) a compreensão de equipes de docentes a respeito da complexidade envolvida nessas contradições, o que implica a contribuição de várias especialidades do conhecimento, ou seja, de uma abordagem interdisciplinar; (3) procurar obter as compreensões de estudantes e de representantes de moradores da localidade sobre as situações vividas e que envolvem as manifestações locais das contradições que foram detectadas e que, na perspectiva da alteridade, serão explicações incluídas para serem problematizadas no planejamento do currículo; e (4) estabelecer planos de ações dialógico-problematizadoras ao longo do desenvolvimento do currículo tal que cada uma das disciplinas que o constitui, e considerando as contribuições específicas que cada uma pode dar para a compreensão das situações vividas, de modo que aprendizes possam vir a compreendê-las na perspectiva de uma consciência máxima possível. De fato, o desafio curricular enfrentado pelos MRC implementados em redes de ensino público está em ir estabelecendo totalizações entre partes examinadas que constituem as manifestações locais de contradições globais. 


\section{O outro na dialogicidade problematizadora}

Silva (2004), tendo como fundamentos as considerações de Enrique Dussel, filósofo argentino, explicitou a dimensão axiológica subjacente aos MRC. Dussel, que precisou se exilar no México em 1975, devido à perseguição da ditadura militar na Argentina, lecionou na Universidad Autónoma de México e se dedicou ao problema da ética da libertação (Dussel, 2000) de países colonizados por europeus, em particular os do continente americano.

Dussel (2000) desenvolve o que denomina de eurocentrismo. Este é densa e aprofundadamente caracterizado no livro, assim como suas relações com a globalização e com a exclusão, referindo-se às pessoas excluídas como vítimas. $\mathrm{O}$ autor sintetiza o eurocentrismo:

[A] tese, que chamarei de "paradigma eurocêntrico" (por oposição ao "paradigma mundial"), é a que se impôs não só na Europa ou nos Estados Unidos, mas também em todo o mundo intelectual da periferia mundial. Como dissemos, a divisão "pseudocientífica" da história em Idade Antiga (como o antecedente), Idade Média (época preparatória) e Idade Moderna (Europa) é uma organização ideológica e deformante da história. A filosofia e a ética precisam romper com esse horizonte redutivo para poder abrir a reflexão ao âmbito "mundial", planetário; este já é um problema ético de respeito a outras culturas. (Dussel, 2000, pp. 5152, grifo nosso).

Particularmente em relação à Ciência Moderna, associada ao surgimento da Idade Moderna, na Europa, e interpretada por Dussel como uma divisão "pseudocientífica", pode-se destacar o papel do islamismo na península ibérica com a invasão árabe, que se manteve durante o período compreendido entre o século VIII e o XV, portanto em plena vigência do período medieval europeu. Coggiola (2011, p. 7), por exemplo, afirma que: "Foram os árabes que espalharam pela Europa grandes nomes como o de Aristóteles, e também outros nomes da antiguidade grega."

A influência da cultura árabe na Europa é considerada em vários estudos. Koestler (1961) faz uma apropriada síntese do que representou a disseminação pela Europa medieval tanto da filosofia grega como de conhecimentos sobre a natureza, originados em outras localidades do mundo, e que influenciaram sobremaneira o que viria a ser, na Idade Moderna europeia, a criação da Ciência Moderna:

[...] alguns dos tratados científicos de Aristóteles, inclusive a Física, haviam sido traduzidos do original grego para o sírio, do sírio para o árabe, do árabe para o hebraico e, finalmente, do hebraico para o latim medieval. O Almagesto de Ptolomeu era conhecido em várias traduções árabes através do império de Harum-al-Rachid, desde o Indo até o Ebro, antes que Gerardo de Cremona, em 1175, o retraduzisse do árabe para o latim. Os Elementos de Euclides foram redescobertos para a Europa por um monge inglês, Adelardo de Bath, o qual, por volta de 1120, achou uma tradução árabe em Córdoba. Recuperados Euclides, Aristóteles, Arquimedes, Ptolomeu e Galeno, a ciência podia recomeçar onde fora interrompida um milênio antes." (Koestler, 1961, p. 67, grifo nosso) 
Deste modo, Koestler (1961) destaca, em sintonia com outros historiadores, que a produção cultural que ocorria na Europa, situada ao norte do mar Mediterrâneo, durante o seu período medieval, foi distinta da produção cultural originada em outras localidades, inclusive em outros continentes, sobretudo no que diz respeito às interpretações de alguns fenômenos naturais. $\mathrm{O}$ impacto dessas circulações de conhecimentos entre distintos povos possibilitou o surgimento de outros que caracterizaram a construção da Ciência Moderna (C. M.), tanto os que por ela foram superados através de um significativo embate filosófico e epistemológico, a exemplo do ocasionado nas discussões sobre o geocentrismo ptolomaico, como os que a ela foram incorporadas.

Contudo, o nascimento da C. M. tem outro componente além dessa circulação intercultural devido às interações entre povos com distintas culturas. Bernal (1976), que também estabelece relações com essa dimensão intercultural, caracteriza de modo pertinente os problemas enfrentados a partir do período final da Idade Média europeia e suas relações com a gênese da C.M. Assim, ele analisa fatos históricos e argumenta que, no período compreendido entre 1440 e 1690, houve um amplo movimento cultural que se dedicou ao enfrentamento de problemas que, "representaram a transição da economia feudal à economia capitalista" na Europa (Bernal, 1976, p. 372). Relaciona, por consequência, as contribuições de Copérnico, Kepler e Galileu, dentre outros, inclusive as de artesãos de distintas corporações e de artistas do Renascimento, para a busca de soluções desses problemas.

Não obstante Dussel (2000) seja um crítico do que denomina de "paradigma eurocêntrico", pelo reducionismo que redunda na sua adoção estritamente paradigmática, na argumentação que aprofunda ao longo do livro distingue verdade e validade expressadas nos conhecimentos contidos nas teorias que se ocupam dos fenômenos naturais. Compartilhando com Freire, se afina com a perspectiva do criticismo, enquanto concepção filosófico/gnosiológica sobre a possibilidade do conhecer. Portanto, também defende, de modo aprofundado, que o conhecimento, inclusive o das ciências da natureza e o das ciências sociais, é incompleto, é devir. Premissa também assumida por alguns filósofos da ciência que têm matizes filosófico-epistemológicos distintos do que é concebido por Freire e Dussel, tais como Bachelard e Popper. Essa incompletude, no entanto, conforme a caracteriza, não se confunde com a validade do conhecimento quando subsidia o enfrentamento de problemas por seres humanos. Nesse sentido, pondera que:

As "ciências" formais (se são ciência) ou de conteúdos ("naturais") podem propor-se intencionalmente certos "objetivos" em seu "programa de investigação" que tem relação mediata (não porém "externa", pois são "meios" para "fins") com as necessidades não satisfeitas das vítimas. ... Quando um matemático se propõe resolver matematicamente certas equações que são as mediações formais necessárias, por exemplo, para o desenvolvimento de uma técnica específica para camponeses pobres na África, que necessita por seu turno que se desenvolvam novos capítulos científicos abstratos, pode-se falar de uma escolha "ética" desse 
"objetivo" (motivada pelas necessidades das vítimas), que modificou ou até inovou o seu antigo "programa". É isto que analisava com razão Oscar Varsavsky na sua obra Ciencia, política y cientificismo (Varsavsky, 1971). (Dussel, 2000, p. 499, grifo nosso).

A referência a Varsavsky, também argentino, deve-se ao fato de que ele é um dos representantes do Pensamento Latino-Americano em Ciência Tecnologia e Sociedade (PLACTS), um grupo de pesquisadores que, conforme informam Auler e Delizoicov (2015),

[...] já nas décadas de 60 e $70, \ldots$ afirmavam que a dinâmica do desenvolvimento científico-tecnológico era alheia, isto é, ignorava as demandas do conjunto da sociedade latino-americana. Propõem a concepção de uma política científicotecnológica (PCT), de agendas de pesquisa a partir de demandas da maioria da sociedade, historicamente relegadas. (Auler \& Delizoicov, 2015, p. 277, grifo nosso).

De fato, nas décadas de 1960 e 1970 emerge uma quantidade significativa de posicionamentos que enfatizam, com críticas relevantes, o papel da Ciência e da Tecnologia (CT) para o desenvolvimento dos países do Terceiro Mundo, como eram denominados na época, por exemplo, os da América Latina. Anderson e Bazin (1977) organizaram o livro Ciência e (IN)dependência, cujo título expressa a ideia da duplicidade implicada nas finalidades da CT nas suas relações com os problemas investigados. LeiteLopes (1977), físico brasileiro e autor do capítulo "Ciência, educação e desenvolvimento para que sociedade?", um dos que compõem o livro citado, assim se expressa ao concluir sua análise:

[...] quando se atingir um novo equilíbrio no mundo pela ruptura do domínio e da injustiça social, a ciência, a investigação científica e os métodos educativos modificar-se-ão igualmente. ... De momento, se os homens [e as mulheres] de ciência não podem transformar o mundo, podem, ao menos - sobretudo os [e as] cientistas do Terceiro Mundo -, contribuir para a análise da situação em que se encontram os seus países e tentar compreender o significado social dos seus próprios trabalhos. (Leite-Lopes, 1977, p. 18).

Posição semelhante às de Dussel (filósofo), Varsavsky (químico e matemático) e Leite Lopes (físico) é assumida por Freire (educador). No livro Cartas à Guiné Bissau, por exemplo, no qual estabelece profícua interação com Mário Cabral, então Comissário da Educação da Guiné Bissau, sobre os caminhos que estavam sendo construídos para a educação naquele país, argumenta:

[...] no ano letivo de 1975 tinham sido iniciadas experiências ... de integração do trabalho produtivo às atividades escolares normais, no intuito de combinar trabalho e estudo, ... é possível fazer derivar da atividade produtiva, cada vez mais, os conteúdos programáticos de "n" disciplinas que, no sistema tradicional, são "transferidos", quando são, verbalistamente. (Freire, 1978, p. 21). 
Quanto às disciplinas de ciências da natureza na articulação desejada, e que ambos defendem, a respeito dos conteúdos de disciplinas ensinadas na escola, Freire destaca:

[...] direi agora, num quase parêntese, que não trairei o espírito do Comissariado de Educação da Guiné-Bissau, afirmando que a importância, várias vezes ressaltada nestas páginas, que ele vem dando e pretende dar à gradual formação científica dos educandos, de que resulte cada vez mais uma compreensão critica de sua realidade, ao atuar sobre ela, não tem nada que ver com uma posição cientificista. ... me parece que um dos aspectos básicos do sistema de educação constituindo-se é o chamamento que vem fazendo aos educandos para, ao lado de sua indispensável formação científica e concomitantemente com ela, numa prática adequada, desenvolverem a solidariedade, a responsabilidade social, o gosto do trabalho livre, como fonte de conhecimento, na produção do socialmente necessário, a camaradagem autêntica e não a competição que o individualismo gera. (Freire, 1978, p. 43, grifo nosso).

Com efeito, Freire, ao considerar a educação científica dos estudantes guineenses, após a libertação, a diferencia fundamentalmente da que era oferecida para os poucos que frequentavam a escola colonialista. Sua compreensão é sintetizada a seguir:

$\mathrm{Na}$ verdade, não seria realizável uma educação voltada para a concretização de valores como a solidariedade, a responsabilidade social, a criatividade, a disciplina a serviço do interesse comum, a vigilância, o espírito crítico, ... se nesta educação os educandos continuassem a ser, como na educação colonial, meros recipientes de "conhecimentos empacotados", a eles transferidos pelos educadores. Puros objetos, incidências da ação "educativa" dos educadores. (Freire, 1978, p. 40).

Portanto, não se trata de desconsiderar as contribuições que explicações e conceituação científicas possam oferecer para o enfrentamento de situações vividas e que precisam ser superadas pelo país que foi, desde o século XV até sua independência, em 1974, colônia de Portugal.

A inserção de conhecimentos científicos na programação, numa perspectiva dialógico-problematizadora, como a defendida por Freire, trata assim da construção de uma práxis educativa que contribua para o processo de superação dos problemas, relacionados às contradições, com os quais convivem as pessoas nos locais que habitam. É a dimensão intercultural que se torna presente na interdisciplinaridade da programação com a qual se desenvolvem as ações educativas.

Dussel, compartilhando das expectativas desses cientistas e de uma possível e desejável atuação no sentido que por eles vinha sendo apontado, dedica-se ao estudo da dimensão filosófica que subjaz a esses posicionamentos, enfatizando tanto a perspectiva axiológica como a gnosiológica. É o que expressam os títulos dos seus livros: Método para uma filosofia da libertação (Dussel, [1974], 1986), Filosofia da Libertação: crítica à ideologia da exclusão (Dussel, 1995) e Ética da libertação na idade da globalização e exclusão (Dussel, 2000). 
É neste último que Dussel (2000) se dedica a analisar as relações das concepções de Freire com a fundamentação filosófica que constrói, destacando a sintonia fina do educador brasileiro com a dimensão ético-critica que é por ele, Dussel (2000), aprofundada para a conscientização que precisa ocorrer em processos educativos, de modo a se caminhar no sentido do ser mais.

\section{Alteridade como princípio curricular ético-crítico}

Assumir a alteridade como princípio curricular evidentemente ocasionará reflexos que vão além daqueles restritos ao Ensino de Ciências. Exige como premissa assumirmos um posicionamento ético em relação à práxis educativa.

No contexto educativo, a alteridade, como já comentado, pode se manifestar em diferentes perspectivas. Pode ser compreendida como conhecer o diferente para "domesticá-lo" a partir de valores privilegiados a priori por determinada cultura, assumindo muitas vezes, um posicionamento passivo de respeito, de tolerância, mas posicionando o "outro" na subalternidade, como alguém que precisa ser convencido de que seus saberes e visões de mundo são equivocados e, portanto, precisam ser esquecidos. A prática curricular vai, assim, estar eivada de imposições epistemológicas, axiológicas e ontológicas. Exige-se a passividade e o conformismo do "outro" para a eficiência do processo formativo da subserviência social e cultural adaptativa. A partir de um discurso supostamente humanista, não se veiculam apenas conhecimentos selecionados e considerados necessários. Impõem-se, também, valores que tentam coisificar sujeitos negados em seus discursos e em suas materialidades na realidade concreta. É o que se destacou em Freire, nas citações anteriores, oriundas das suas interlocuções com o Comissariado da Educação da Guiné-Bissau.

Além da fome, do desemprego e de outras mazelas, cada vez mais divulgadas midiaticamente, relacionadas à materialidade das contradições, é fundamental enfatizar, como exemplo pertinente, a desfaçatez da sociedade e do Estado brasileiros com a educação escolar no Brasil ao longo da sua História. Há, assim, um posicionamento axiológico que é historicamente excludente, tanto pelos valores que impediram a democratização do acesso à educação escolar pública, como pela imposição daqueles implícitos ou explícitos em concepções curriculares que nem sempre estão em sintonia com a promoção de um ser mais, conforme concebe Freire. Alcançar a condição de ser mais demanda, de acordo com Freire e Shor (1987), assumir o seguinte posicionamento político-pedagógico para o ensino das áreas do conhecimento:

Se o Banco Mundial exige de um país de terceiro mundo 'austeridade' que implica em baixos salários, podemos discutir em uma aula de Biologia as implicações dessa medida para a dieta alimentar e a saúde. Todas essas análises iluminam a realidade. (Freire \& Shor, 1987, p. 35).

Faz-se, portanto, necessário diferenciar a ética dos princípios filosóficos que fundamentam a moral, ou seja, explicitar a relação dialética que se estabelece entre os dois conceitos. Como destaca Vázquez: 
A ética não cria a moral. [...] A ética depara com uma experiência históricosocial no terreno da moral, ou seja, com uma série de práticas morais já em vigor e, partindo delas, procura determinar a essência da moral, sua origem, as condições objetivas e subjetivas do ato moral. (Vázquez, 1998, p. 12)

De forma explícita ou implícita, a dimensão ética apresenta-se como uma referência constante em todas as práticas materiais, culturais e sociais da vida humana, já que desvela as dimensões ontológicas de sua existência. Portanto, a educação nunca pode desconsiderá-la. Conforme Dussel:

A vida humana é o modo de realidade do sujeito ético [...], que dá o conteúdo a todas as suas ações, que determina a ordem racional e o nível das necessidades, pulsões e desejos, que constitui o marco dentro do qual se fixam fins. (Dussel, 2000, p. 131)

Para o autor, só uma ética efetivamente comprometida com a concretude da vida, uma ontologia que reconheça a exigência ao cumprimento do direito na produção, reprodução e desenvolvimento da existência humana, independentemente de distinções ou diferenças, pode ser considerada uma ética crítica humanizadora. É na positividade ética da alteridade que se afirma o processo de construção do ser mais. Como destaca Dussel:

Para a consciência crítica, que só pode existir a partir de uma posição ética bem específica, e pelo exercício de um novo tipo de racionalidade [...], as vítimas são re-conhecidas como sujeitos éticos, como seres humanos que não podem reproduzir ou desenvolver sua vida, que foram excluídos da participação na discussão, que foram afetados por alguma situação de morte. (Dussel, 2000, p. 303)

O reconhecimento, a compreensão e o compromisso com esse "outro" é uma exigência para uma práxis curricular ético-crítica humanizadora. Dussel (1995, p. 46) argumenta que esse "outro encontra-se em uma posição de exterioridade em relação à totalidade hegemônica do sistema-mundo", excluído na dimensão material, individual, cultural, epistemológica, sociológica e econômica. Em decorrência do compromisso com a perspectiva ético-crítica curricular, precisamos assumir a necessidade de que todos os envolvidos nos diferentes segmentos da comunidade escolar - aprendizes, docentes, demais profissionais, pais e mães, bem como demais representantes da população que habitam o entorno da escola - tornem-se sujeitos da práxis curricular humanizadora a partir das situações-limite (Vieira-Pinto, 1960; Freire, 1988) presentes na materialidade da realidade concreta para o desenvolvimento da vida.

Dussel (2000) enfatiza como a alteridade é contemplada na pedagogia freireana em sua dimensão ético-crítica. Nesse sentido, ao analisar a concepção de práxis libertadora na obra do autor, afirma: 
Freire insiste em que a análise teórica das causas da opressão do oprimido é o meio pelo qual este toma consciência da realidade objetiva que produz a sua opressão, permitindo lhe uma apreensão explicativa mínima do argumento de caráter reflexivo, teórico, crítico. [Para Freire ...] O ato pedagógico só se dá dentro do processo da práxis de libertação, que não é só um ato revolucionário, mas todo ato transformativo humanizante em prol dos oprimidos e para que deixem de ser oprimidos. (Dussel, 2000, pp. 439-443).

Na perspectiva curricular anunciada por Freire (1988), na dinâmica metodológica da Investigação Temática, já anunciada anteriormente, manifestam-se princípios e diretrizes para se construir currículos e programações a partir do compromisso com a humanização do "outro". O porquê e o para que direcionam o sobre o que e o como sistematizar o processo de ensino-aprendizagem. $\mathrm{O}$ autor assume a seguinte posição ética e política:

[...] não me parece possível nem aceitável a posição ingênua ou, pior, astutamente neutra de quem estuda, seja o físico, o biólogo, o sociólogo, o matemático, ou o pensador da educação. Ninguém pode estar no mundo, com o mundo e com os outros de forma neutra. Não posso estar no mundo de luvas nas mãos constatando apenas. A acomodação em mim é apenas caminho para a inserção, que implica decisão, escolha, intervenção na realidade. (Freire, 1996, p. 30).

Silva (2004) procura sistematizar as dimensões ético-críticas dos diferentes momentos do processo de investigação temática. O autor busca evidenciar como a alteridade ético-crítica está dialogicamente presente: na seleção dos objetos de estudo; na apreensão da realidade local em um contexto sociocultural e econômico mais amplo; na seleção crítica dos conhecimentos universais sistematizados que estarão a serviço do desvelamento do real-concreto codificado; e, por último, na sistematização da práxis curricular dialógica nos momentos de ensino-aprendizagem.

No presente texto, como anteriormente anunciado, busca-se enfatizar como a alteridade na perspectiva curricular ético-crítica é considerada fundamento ontológico, axiológico e epistemológico em relação aos princípios e diretrizes na práxis da dialogicidade, da problematização e da interdisciplinaridade que se inter-relacionam e perpassam todo o processo de construção curricular ético-crítico.

Sem dúvida, o diálogo é uma categoria central na pedagogia ético-crítica freireana (Freire, 1988). O diálogo, para o autor, vai além de uma questão pedagógica e epistemológica, é uma exigência gnosiológica para uma aprendizagem que promova a construção de um conhecimento crítico, praxiologicamente autêntico. $O$ diálogo ético freireano assume o compromisso com o "outro" de haver uma prática educativa humanizadora que resista às tentativas de homogeneização dos sujeitos e vise à construção coletiva com o intuito de promover a transformação da realidade concreta, injusta e eivada de desigualdades e injustiças. Ou seja, a dialogicidade pedagógica pode ser compreendida como um encontro ético-crítico entre diferentes sujeitos interdependentes 
em busca da superação das contradições sociais historicamente situadas, e a alteridade é o princípio e a diretriz do diálogo. São sucessivas tentativas de se partilhar sentidos e significados críticos sobre um mesmo objeto a ser recriado.

A alteridade manifesta na voz do "outro" sobre seus limites na realização da vida é a referência e é quem inaugura a práxis dialógica que se substancia na postura aberta ao discurso coletivo. Como nos lembra Freire:

Viver a abertura respeitosa aos outros e, de quando em vez, de acordo com o momento, tomar a própria prática de abertura ao outro como objeto da reflexão crítica deveria fazer parte da aventura docente. A razão ética da abertura, seu fundamento político, sua referência pedagógica; a boniteza que há nela como viabilidade do diálogo. A experiência da abertura como experiência fundante do ser inacabado que terminou por se saber inacabado. (Freire, 1988, p. 153)

É a partir das demandas da alteridade, que as vozes denunciam, que se busca estabelecer um diálogo em que o educador precisa fazer uso de critérios epistemológicos, éticos e políticos para fundamentar seu discurso crítico de contraponto sobre as situações contraditórias em análise, indo além de uma abordagem cognitivista estritamente psicologizante. É o acesso dirigido e intencional aos acervos dos conhecimentos universalmente sistematizados que propiciará a construção de outra perspectiva para os limites na apreensão da realidade presente nas vozes do "outro", possibilitando vislumbrar superações nas reflexões e práticas socioculturais conformistas anteriormente realizadas.

O desafio que se apresenta ao se promover o diálogo a partir das alteridades é que ele não reproduza os métodos de uma educação autoritária em que a visão do educador e sua concepção de realidade é imposta ao outro como se fosse a única perspectiva relevante ou uma solução de problemas a partir de respostas preestabelecidas. Uma proposta éticocrítica para o diálogo exige a dinâmica epistemológica da problematização, a segunda categoria de reflexão no presente texto.

Portanto, não se trata de buscar alternativas didáticas motivacionais ou de facilitar a importância de uma temática/conteúdo a priori determinados pelo educador, mas de um posicionamento político-pedagógico que convida o "outro" a refletir sobre as condições materiais e socioculturais concretas que vivencia. Assume-se, então, uma racionalidade problematizadora como uma exigência axiológica. Em relação a essa concepção de problematização, destaca Freire:

A problematização não é [...] um entretenimento intelectualista, alienado e alienante; uma fuga da ação; um modo de disfarçar a negação do real. [...] Inseparável do ato cognoscente, a problematização se acha como este inseparável das situações concretas. [...] Esta é a razão pela qual, partindo destas últimas, cuja análise leva os sujeitos a reverem-se em sua confrontação com elas, a refazer esta confrontação, a problematização implica num retorno crítico à ação. Parte dela e a ela volta. [...] Deste modo, a concepção educativa que defendemos [...] gira em torno da problematização do homem-mundo. Não em torno da 
problematização do homem isolado do mundo nem da deste sem ele, mas de relações indicotomizáveis que se estabelecem entre elas. (Freire, 1977, pp. 82-83)

Nesse sentido, as negatividades presentes nas condições concretas da vida humana, suas dimensões material, cultural e social, denunciadas no discurso concreto do "outro", constituem o sentido e a intencionalidade da práxis curricular ético-crítica. São a razão de ser da seleção dos conteúdos que vão compor a prática pedagógica problematizadora. Nessa perspectiva, ainda, para Dussel:

A condição de possibilidade do conhecer a 'negação originária' sofrida pela vítima consiste numa 'afirmação' prévia a partir da qual se recorta a 'negação'. Não é possível a crítica ao sistema existente, sem o 're-conhecimento' do outro (da vítima) como sujeito autônomo, livre e dis-tinto (não só igual ou di-ferente). O 're-conhecimento' do Outro, graças ao exercício da razão ética pré-originária é anterior à crítica e anterior ao argumento (à razão discursiva ou dialógica); está na origem do processo e já é afirmação da vítima como sujeito, que é negada. (Dussel, 2000, p. 374)

Ou seja, o processo problematizador do diálogo estabelece parâmetros éticocríticos e político-epistemológicos para a sistematização de programações e atividades pedagógicas que direcionam a construção coletiva para a práxis social transformadora momento de redução temática segundo Freire (1988). Portanto, é relevante aprofundar a concepção do que seja conteúdo escolar. Como afirma Delizoicov:

A priori não haveria um conteúdo programático pronto, mas sim conhecimentos científicos acumulados historicamente que seriam selecionados, e que deveríamos socializar, enquanto direito do educando deles se apropriar. [...] Nosso objetivo se constituía em construir programas a partir da investigação temática e da consequente redução temática, garantindo o caráter dialógico quer da programação a ser construída, quer da sua abordagem na sala de aula com os alunos. (Delizoicov, 1991, p. 177)

A racionalidade problematizadora fundamenta-se na análise de uma posição teórico-metodológica ético-crítica (Dussel, 2000) que assume a necessidade material do "outro", manifesta na voz do "outro", os conflitos culturais ideologizados presentes em suas representações de realidade, buscando concebê-los como contradições sociais que demandam planos de ação transformadores. $\mathrm{O}$ autor sistematiza os sentidos e significados do processo de construção de um conhecimento ético-crítico em sua Tese 11:

Por sobrevivência humana ou por 'produção, reprodução e desenvolvimento da vida humana de cada sujeito ético' entenderemos [...] o critério material universal da ética por excelência: a vida humana concreta de cada ser humano. Isto deve ser exposto em três momentos: a) $\mathrm{O}$ da produção da vida humana, nos níveis vegetativo ou físico, material [...] e por meio e contendo [...] as 
funções superiores da mente (consciência, autoconsciência, funções linguísticas, valorativas, com liberdade e responsabilidade ética, etc.), como processo inicial que é continuado no tempo pelas instituições na 'reprodução' (histórico, cultural etc.). É o âmbito próprio da razão prático-material. b) O da reprodução da 'vida humana' nas instituições e nos valores culturais: vida 'humana' nos sistemas de eticidade históricos motivados pelas pulsões reprodutivas. É o âmbito da razão 'reprodutiva'. c) O do desenvolvimento dessa vida 'humana' no quadro das instituições ou culturas reprodutivo-históricas da humanidade. [...] É o âmbito da razão ético-crítica. (Dussel, 2000, p. 636)

Nesse sentido, a racionalidade problematizadora que perpassa o diálogo freireano como mote epistemológico é uma exigência curricular ético-crítica com a humanização a partir da alteridade. O compromisso gnosiológico revela a práxis humanizadora autêntica. Como nos lembra Freire:

O que importa fundamentalmente à educação, contudo, como uma autêntica situação gnosiológica, é a problematização do mundo do trabalho, das obras, dos produtos, das ideias, das convicções, das aspirações, dos mitos, da arte, da ciência, enfim, o mundo da cultura e da história, que, resultando das relações homem-mundo, condiciona os próprios homens, seus criadores. [...] Colocar este mundo humano como problema para os homens significa propor-lhes que 'ad-mirem', criticamente, numa operação totalizada, sua ação e a de outros sobre o mundo. [...] Aí reside toda a força da educação que se constitui em situação gnosiológica. (Freire, 1988, p. 83)

A racionalidade problematizadora da práxis pedagógica ético-crítica procura desenvolver uma investigação coletiva sobre as necessidades para a sobrevivência dos sujeitos da comunidade - produção, reprodução e desenvolvimento (Dussel, 2000). São adotados, enquanto objetos de estudo, a forma passiva como, muitas vezes, os conflitos são compreendidos mas que, no entanto, podem ser apreendidos como contradições sociais, quando analisadas à luz dos conhecimentos universalmente sistematizados. Para tanto, é fundamental resgatar as contribuições das diferentes áreas do conhecimento.

Por fim, voltamos a abordar a relevância da interdisciplinaridade no diálogo e na problematização em uma perspectiva educacional que assume a alteridade como um princípio político-pedagógico.

Nesse contexto, a interdisciplinaridade na abordagem curricular deixa de ser um recurso estritamente epistemológico, uma reflexão sócio-histórica da gênese da ciência ocidental, para assumir a necessidade de interpretar a realidade concreta em suas múltiplas dimensões e significados. Não se trata de buscar uma abordagem filosófica e histórica sobre as epistemologias referentes à produção científica, mas uma necessidade para compreender a realidade a partir de sucessivas totalizações em que a articulação entre áreas distintas do conhecimento, quando articuladas, são capazes de contribuir para o desvelamento da concretude da vida humana em diferentes contextos e para a criação da práxis transformadora. 
É a análise crítica da realidade no contexto da alteridade que exige uma postura curricular interdisciplinar. Como anteriormente salientado, Pernambuco (1994), partindo da concepção de interdisciplinaridade de Freire (1988), apresenta possíveis relações entre a construção curricular ético-crítica na análise do real e a diversidade como uma exigência para abordagens interdisciplinares no processo de ensino-aprendizagem crítico. Um projeto curricular que parta de tais dificuldades denuncia, nas diferentes dimensões da práxis curricular, como as relações de opressão axiológicas se concretizam na convivência entre os sujeitos na organização metodológica de programações interdisciplinares de práticas pedagógicas eticamente comprometidas com as demandas da alteridade negligenciada e desfavorecida. Assim compreendido, o processo de acesso e recriação do conhecimento sistematizado disponível, de forma interdisciplinar, apresenta uma relevância fundamental na prática educativa comprometida com a formação ética dos cidadãos e com as transformações humanizadoras da realidade concreta. Ou seja, não há práxis curricular ético-crítica comprometida com a alteridade que não adote uma postura epistemológica interdisciplinar.

Destaca-se que esse movimento de reorientação curricular comprometido com a alteridade na práxis ético-crítica autêntica, como aqui salientados para o ensino de ciências da natureza, deva pautar-se pelas necessidades inerentes da alteridade, envolvendo diálogos problematizadores que demandem culturas e conhecimentos interdisciplinares para a recriação das concepções de mundo ideologicamente obstaculizadas na cotidianidade comunitária que, muitas vezes, impossibilitavam as transformações humanizadoras do contexto concreto vivenciado.

Em síntese, trata-se de um movimento curricular dialógico - problematizador em que se parte de necessidades práticas, compreendidas como conflitos socioculturais, na perspectiva de desencadear um distanciamento que permita identificar as tensões entre conhecimentos abordados de forma interdisciplinar, visando ao desvelamento e à superação de contradições sociais concretas.

\section{Considerações finais}

Para a práxis da alteridade freireana, há a necessidade de uma sintonia com os pressupostos ético-críticos fundamentados por Dussel ([1974]1986, 1995, 2000). Isso implica que educadoras e educadores, como também pesquisadoras e pesquisadores dedicados à educação em ciências, para além da dimensão epistemológica, adotem uma perspectiva axiológica que considere, como defende Dussel (2000, p. 636), um compromisso ético com "a produção, reprodução e desenvolvimento da vida humana", ou seja, com o ser mais humano, conforme a ontologia freireana. A perspectiva se articula com a concepção segundo a qual o conhecimento é incompleto. É, portanto, a historicidade do conhecer, tanto o das ciências da natureza como o de outras áreas, também, e sobretudo, o de estudantes, que dão o foco para os conhecimentos que pautam o processo educativo para compreensões das manifestações locais de contradições globais. Trata-se, assim, de conceber o conhecimento incompleto na sua dimensão 
espaço-temporal. Em outros termos, ele precisa estar articulado por parâmetros não só históricos mas também geográficos, ou seja, o que Santos $(1982,1977)$ caracteriza como a formação social do espaço. Ele afirma que:

Se a Geografia deseja interpretar o espaço humano como o fato histórico que ele é, somente a história da sociedade mundial, aliada à da sociedade local, pode servir como fundamento à compreensão da realidade espacial e permitir a sua transformação a serviço do homem. Pois a História não se escreve fora do espaço e não há sociedade a-espacial. O espaço, ele mesmo, é social. (Santos, 1977, p. 1, grifo nosso).

Outro aspecto a ser considerado na perspectiva ético-crítica da alteridade freireana diz respeito à necessária articulação que se faz entre a seleção conceitual que estrutura a perspectiva interdisciplinar do currículo e suas relações com a cognição. Evidente que a compreensão do processo de cognição relacionado ao ensino e à aprendizagem conceitual precisa estar em sintonia com a construção e implementação curricular dedicada a uma compreensão das contradições que limitam o desiderato do ser mais humano. O fato da conceituação contida nas teorias científicas ter sido incorporada num currículo interdisciplinar, originado para possibilitar compreensões que estudantes ainda não têm de situações reais vividas e que se referem às manifestações locais de contradições globais, parece introduzir uma dimensão nova a ser investigada no que se refere à influência desse contexto de construção curricular no processo cognitivo. A conceituação científica necessária e pertinente foi inserida na articulação dialógico-problematizadora que envolve uma negociação dialógica entre especialistas responsáveis por cada uma das disciplinas para a compreensão conjunta e articulada das situações. Além disso, as situações são reais, no sentido de terem sido abstraídas por docentes, especialistas em distintas áreas, com procedimentos que possibilitam obter informações através de dados empíricos. Não obstante isso, outro importante elemento constituinte do contexto curricular interdisciplinar é a própria compreensão manifestada por estudantes sobre essas situações incluídas no planejamento e na programação das atividades educativas, de modo que numa dinâmica dialógica possa ser problematizada e contribuir para uma compreensão oferecida pela estruturação conceitual pertinente originada do conhecimento científico.

O planejamento de ensino, portanto, referente aos conceitos científicos, estabelece relações entres bases conceituais constituídas historicamente, por distintas áreas do conhecimento e que são articuladas entre si pelas situações vividas, originadas das manifestações locais das contradições que desumanizam, desde que elas não propiciam o ser mais humano. Usando uma figura de linguagem, podemos dizer que o planejamento do ensino de conceitos assim relacionados é uma rede em construção, que representaria situações contraditórias e cujos nós, os conceitos específicos com os quais se tece essa rede, é que contribuem tanto para atribuir significados uns para os outros (conceitos), como para construir e significar a própria rede. Pretende-se que esses significados sejam constituídos pela aprendizagem, através de um planejamento didático com base na dialogicidade e na problematização. 
Parece haver, portanto, a necessidade de investigações dos processos cognitivos decorrentes das opções relacionadas às articulações estabelecidas entre esta concepção curricular interdisciplinar e um planejamento didático cujos fundamentos são a dialogicidade e a problematização. Seria o que Freire $(1977,1988)$ denomina de inédito viável ao se avançar na busca de respostas para as perguntas sobre a cognição que podem ser formuladas a partir dessa práxis educacional ético-crítica.

\section{Referências}

Almeida, M. J. P. M., Oliveira, O., \& Cassiani, S. (2008). Leitura e escrita em aulas de ciências. 1. ed. Florianópolis: Letras Contemporâneas. https://doi.org/10.1590/198321172009110211

Alves-Brito, A., Bootz, V., \& Massonin, N. T. (2018). Uma sequência didática para discutir as relações étnico-raciais (Leis 10.639/03 e 11.645/08) na educação científica. Caderno Brasileiro de Ensino de Física, 35(3), 917-955. https://doi.org/10.5007/21757941.2018v35n3p917

Anderson, S., \& Bazin, M. (1977). Ciência e (IN)dependência II. Livros Horizonte.

Auler, D., \& Delizoicov, D. (2015). Investigação de temas CTS no contexto do pensamento latino-americano. Linhas Críticas, 21(45), 275-296. https://doi.org/10.26512/ lc.v21i45.4525

Bachelard, G. (1977). O Racionalismo Aplicado. Zahar Editores.

Bernal, J. (1976). Ciência na História. Livros Horizonte.

Candau, V. M. (2008). Direitos humanos, educação e interculturalidade: as tensões entre igualdade e diferença. Revista Brasileira de Educação, 13(37), 45-56. https://doi. org/10.1590/S1413-24782008000100005

Coggiola, O. (2011). Islã histórico e islamismo político. Editora Pradense.

Delizoicov, D. (2020). Carta À Piera Brigatti: uma educadora ético-crítica. Crítica Educativa, 6(1), 1-13.

Delizoicov, D. (2008). La Educación en Ciencias y la Perspectiva de Paulo Freire. Alexandria: Revista de Educação em Ciência e Tecnologia, 1(2), 37-62. https://periodicos. ufsc.br/index.php/alexandria/article/view/37486

Delizoicov, D. (1991). Conhecimento, tensões e transições. (Tese de Doutorado, Faculdade de Educação da Universidade de São Paulo, São Paulo, São Paulo). Repositório Institucional da UFSC. http://repositorio.ufsc.br/xmlui/handle/123456789/75757

Delizoicov, D. (1983). Ensino de Física e a concepção freireana da educação. Revista de Ensino de Física, 5(2), 85-98. http://www.sbfisica.org.br/rbef/pdf/vol05a19.pdf

Delizoicov, D., Delizoicov, N. C., \& Silva, A. F. G. (2020). Paulo Freire e o ser humano em processo de formação permanente. Revista Retratos da Escola, Brasília, 14(29), 353-369. https://doi.org/10.22420/rde.v14i29.1155 
Delizoicov, N. C., Stuani, G. M., \& Cunha, S. L. da (Orgs.) (2018). A Atualidade das Ideias de Paulo Freire. Editora VIVENS.

Delizoicov, N. C., Stuani, G. M., \& Delizoicov, D. (2013). Reorientação curricular na concepção freireana de educação: análises em dissertações. Revista e-Curriculum, São Paulo, 3(11), 648-712. https://revistas.pucsp.br/index.php/curriculum/article/ view/17880

Dussel, E. (2000). Ética da libertação na idade da globalização e exclusão. Vozes.

Dussel, E. (1995). Filosofia da libertação: crítica à ideologia da exclusão. Paulus.

Dussel, E. ([1974]1986). Método para uma filosofia da libertação. Louyola.

Freire, P. (2010). Pedagogia da autonomia. Saberes necessários à prática educativa. Paz e Terra.

Freire, P. (1996). Pedagogia da autonomia: saberes necessários à prática educativa. Paz e Terra.

Freire, P. (1995). Educação na cidade. Cortez.

Freire, P. (1988). Pedagogia do oprimido. Paz e Terra.

Freire, P. (1978). Cartas à Guiné Bissau. Paz e Terra.

Freire, P. (1977). Extensão ou comunicação?. Paz e Terra.

Freire, P., Shor, I. (1987). Medo e ousadia: o cotidiano do professor. Paz e Terra.

Goldmann, L. (1980). Ciências Humanas e Filosofia. Difusão Editorial.

Leite-Lopes, J. (1977). Ciência, educação e desenvolvimento - para qual sociedade? In S. Anderson, M. Bazin (Org.). Ciência e (IN)dependência (pp. 11-18). Livros Horizonte.

Lemgruber, M. S. (2000). Um Panorama da Educação em Ciências. Educação em Foco, 5(1), 13-28.

Koestler, A. (1961). Os sonâmbulos. Ibrasa.

Oliveira, A. C., Vaniel, B. V., \& Collares, M. P. (27 de Janeiro-01 de Fevereiro, 2019). Ensino de Física: um compromisso com a construção de relações sociais éticas e uma educação antirracista. Simpósio Nacional do Ensino de Física, Salvador: Universidade Federal da Bahia (UFBA).

Oliveira, L. F., \& Candau, V.M.F. (2010). Pedagogia decolonial e educação antirracista e intercultural no Brasil. Educação em revista, 26(1), 15-40. https://doi.org/10.1590/ S0102-46982010000100002

Oliveira, R. D. V. L., \& Queiroz, G. R. P. C. (2017). Conteúdos Cordiais: Química Humanizada para uma Escola sem Mordaça. Livraria da Física.

Oliveira, R. D. V. L., \& Queiroz, G. R. P. C. (2015). Olhares sobre a (in)diferença: formarse professor de ciências a partir de uma perspectiva de Educação em Direitos Humanos. Livraria da Física. 
Oliveira, R. D. V. L., \& Queiroz, G. R. P. C. (2013). Educação em Ciências e Direitos Humanos: reflexão-ação em/para uma sociedade plural. Multifoco.

Pernambuco, M. M. C. A. (1994). Educação e escola como movimento - do ensino de ciências a transformação da escola pública. (Tese de Doutorado, Universidade de São Paulo, São Paulo, São Paulo). Repositório da Produção USP. https://repositorio.usp.br/ item/000739695

Pfund, H., \& Duit R. (1994). Bibliography students' alternative frameworks and Science Education. Institute for Science Education.

Pinheiro, B. C. S. (2019). Educação em Ciências na Escola Democrática e as Relações Étnico-Raciais. Revista Brasileira de Pesquisa em Educação em Ciências, 19, 329-344. https://doi.org/10.28976/1984-2686rbpec2019u329344

Pontuschka, N. N. (Org.). (1993). Ousadia no diálogo - Interdisciplinaridade na escola pública. Loyola.

Sampaio, M. M. F., Zita, A. D. Q., \& Pimentel, P. (1994). Interdisciplinaridade no Município de São Paulo. Série Inovações Educacionais. INEP/MEC.

Santos, B. S., \& Meneses, M. P. (Orgs.). (2010). Epistemologias do Sul. Cortez.

Santos, M. (1982). Espaço e sociedade: Ensaios (2a ed). Vozes.

Santos, M. (1977). Sociedade e espaco: a formacão social como teoria e como método. Boletim Paulista de Geografia, 9(1), 81-99.

Saul, A .M. (2016). Paulo Freire na atualidade: legado e reinvenção. Revista e-Curriculum, 14(1), 9-34. https://revistas.pucsp.br/index.php/curriculum/article/view/27365

Saul, A. M. (2012). O pensamento de Paulo Freire na educação brasileira: análise de sistemas de ensino a partir de 1990. Currículo sem Fronteiras, 12(3), 37-56. https://www. curriculosemfronteiras.org/vol12iss3articles/saul.pdf

Saul, A. M., \& Silva, A. F. G. (2009). O Legado de Paulo Freire para as políticas de currículo e para a formação de educadores no Brasil. Revista Brasileira de Estudos Pedagógicos, 90(224), 223-244. https://doi.org/10.24109/2176-6681.rbep.90i224.507

Severino, A. J. (2006). A busca do sentido da formação humana: tarefa da Filosofia da Educação. Educação e Pesquisa, 32(3), 619-634. https://doi.org/10.1590/S151797022006000300013

Silva, A. F. G. (2004). A construção do currículo na perspectiva popular crítica: das falas significativas às práticas contextualizadas. (Tese de Doutorado, Pontifícia Universidade Católica, São Paulo, São Paulo). Biblioteca Digital. https://tede2.pucsp.br/handle/ handle/22098

Steiner, J. (2006). A origem do universo. Estudos Avançados, 20(58), 233-248. 
Torres, C.A., O' Cadiz, M. P., \& Wong, P. L. (2002). Educação e democracia - a práxis de Paulo Freire em São Paulo. Cortez/Instituto Paulo Freire.

Vásquez, A. S. (1998). Ética. Civilização Brasileira.

Vieira-Pinto, A. (1960). Consciência e realidade nacional. ISEB/MEC.

Wortmann, M. L. C., \& Veiga-Neto, A. (2001). Estudos culturais da ciência \& educação. Autêntica Editora.

\author{
Demétrio Delizoicov \\ Universidade Federal de Santa Catarina \\ Florianópolis, Santa Catarina, Brasil \\ demetrio.neto@ufsc.br \\ Antonio Fernando Gouvêa da Silva \\ Universidade Federal de São Carlos (Campus Sorocaba) \\ Sorocaba, São Paulo, Brasil \\ gova@uol.com.br
}

Editora Responsável

Stefannie Ibraim

Manifestação de Atenção às Boas Práticas Científicas e de Isenção de Interesse

Os autores declaram ter cuidado de aspectos éticos ao longo do desenvolvimento da pesquisa e não ter qualquer interesse concorrente ou relações pessoais que possam ter influenciado o trabalho relatado no texto. 